\title{
CAPACITY BUILDING PADA UNIT PROGRAM PEMBINAAN KESEJAHTERAAN KELUARGA (PKK)
}

\section{CAPACITY BUILDING IN THE FAMILY WELFARE PROGRAM (PKK)}

\author{
A Rahmawati ${ }^{1 a}$ dan HS Nugroho' \\ 1Fakultas Ekonomi dan Sosial, Universitas AMIKOM Yogyakarta, Indonesia \\ a Korespondensi: Agustina Rahmawati, Email: agustinarahma@amikom.ac.id \\ (Diterima: 28-11-2017; Ditelaah: 29-11-2017; Disetujui: 25-03-2018)
}

\begin{abstract}
Karangasem Village RT 05 RW 12 is one of the villages in the Condong Catur Village, which is densely populated and still has a large area of rice fields. The livelihood of most of the men there are employees and farm laborers, while the majority of women are housewives. Since its inception, the Family Welfare Development Program (PKK) of the mothers of RT 04 RW 12 is still active, until now there is a Waste Bank Program Unit and a Women's Farmer Group (KWT) formed by the Government. However, the management is still not optimal, especially in KWT units. In the KWT unit according to the PKK Chair, Mrs. Sri Asmoroning there are still deficiencies in the internal organization of the administration and secretarial governance that are still lacking in order, such as correspondence systems and bookkeeping reports. There is also a KWT unit in organizational management that has been formed but does not have a clear division of labor. On that basis, administrative and secretarial training is needed because the organization of miniature community groups is the real organization in the community, so as an activist must learn to manage the organization professionally. The method used in this community service is through lectures and mentoring tutorials. The output of this activity is an increase in the capacity and skills of the organization's management in managing administration and secretariat and the existence of a clear division of labor in the organizational structure of the KWT so as to create an effective responsibility and authority in its management. Both of these are the Capacity Building instruments to support the smooth implementation of organizational tasks carried out by HR unit management programs.
\end{abstract}

Keywords: administration and secretariat, capacity building, organizational institutions.

\begin{abstract}
ABSTRAK
Desa Karangasem RT 05 RW 12 merupakan salah satu desa di Kelurahan Condong Catur yang padat penduduk dan masih memiliki area sawah yang cukup luas. Mata pencaharian sebagian besar kaum pria disana karyawan dan buruh tani, sedangkan mayoritas kaum wanitanya sebagai ibu rumah tangga. Sejak dahulu dicanangkannya Program Pembinaan Kesejahteraan Keluarga (PKK) ibu-ibu RT 04 RW 12 masih aktif, hingga sekarang terdapat Unit Program Bank Sampah dan Kelompok Wanita Tani (KWT) yang dibentuk Pemerintah. Namun, pada pengelolaannya masih belum optimal terutama pada unit KWT. Di dalam unit KWT menurut Ketua PKK Bu Sri Asmoroning masih terdapat kekurangan dalam internal organisasi yakni pada tata kelola administrasi dan kesekretariatan yang masih kurang tertib seperti sistem surat menyurat maupun laporan pembukuan. Adapula pada unit KWT kepengurusan organisasi telah terbentuk namun belum memiliki pembagian kerja yang jelas. Atas dasar itu, diperlukan pelatihan administrasi dan kesekretariatan sebab organisasi kelompok masyarakat miniatur organisasi yang sesungguhnya di masyarakat, maka sebagai
\end{abstract}


penggiatnya harus belajar mengelola organisasinya secara profesional. Metode yang digunakan dalam pengabdian masyarakat ini yakni melalui ceramah dan tutorial pendampingan. Luaran kegiatan ini yakni adanya peningkatan kemampuan dan skill pengurus organisasi dalam mengelola administrasi dan kesekretariatan serta adanya pembagian kerja yang jelas dalam struktur organisasi KWT sehingga tercipta tanggungjawab dan wewenang yang efektif dalam kepengurusannya. Kedua hal tersebut merupakan instrumen Capacity Building fungsi penunjang kelancaran pelaksanaan tugas- tugas organisasi yang dilakukan oleh SDM pengelola unit program.

Kata kunci: administrasi dan kesekretariatan, capacity building, kelembagaan organisasi

Rahmawati, A. \& Nugroho, H. S. (2018). Capacity Building pada Unit Program Pembinaan Kesejahteraan Keluarga (PKK). Qardhul Hasan: Media Pengabdian kepada Masyarakat 4(1): 41-47.

\section{PENDAHULUAN}

Wanita memiliki peran vital dalam pembangunan. Mengembangkan kelompok wanita sangat penting sebagai strategi untuk memudahkan akses perempuan terhadap informasi, meningkatkan kapasitas mereka untuk ikut dalam pengambilan keputusan serta menciptakan kesempatan sebagai upaya mengakses masukan ekonomi melalui kegiatan bersama. Meningkatnya peran dan produktivitas sebagai pengurus rumah tangga, juga berhubungan erat dengan perannya sebagai pelaku usaha dalam pencapaian ketahanan pangan dan kesejahteraan rumahtangga.

Pada perkembangannya, pemerintah daerah gencar mencanangkan berbagai program pemberdayaan wanita.Salah satunya melalui Pembinaan Kesejahteraan Keluarga (PKK) di berbagai desa. Secara khusus, Pemerintah Daerah Kabupaten Sleman telah mengembangkan unit kegiatan bank sampah dan juga Kelompok Wanita Tani (KWT). Bank Sampah merupakan program pengelolaan sampah terpadu berbasis masyarakat melalui 3R (reuse, reduce, recycle) yaitu kegiatan penggunaan kembali sampah secara langsung, mengurangi segala sesuatu yang menyebabkan timbulnya sampah, memanfaatkan kembali sampah setelah mengalami proses pengolahan. Sedangkan, Kelompok Wanita Tani (KWT) merupakan wadah bagi para wanita agar dapat berhimpun, berusaha dan bekerjasama untuk meningkatkan kesejahteraan keluarga melalui usaha bersama dalam memanfaatkan lahan kosong.Oleh karena itu, masih banyaknya lahan pekarangan kosong diharapkan dapat termanfaatkan secara optimal oleh para ibu rumahtangga.

Dalam pengabdian masyarakat yang akan kami lakukan, kami menentukan lokasi pengabdian yakni di wilayah Karangasem, Desa Condongcatur Kabupaten Sleman. Pada wilayah Karangasem terdapat kelompok yang bergerak di unit kegiatan bank sampah.Kelompok kegiatan bank sampah ini bernama "Kasturi".Kelompok kasturi ini beranggotakan 140 orang. Pada perkembangannya kelompok Kasturi telah meraih beberapa penghargaan, baik di tingkat kabupaten ataupun propinsi, serta di tingkat nasional.AdapunKelompok Wanita Tani (KWT)“Lestari” yang merupakan unit program dari PKK Karangasem. Kelompok wanita tani Lestari didirikan pada November 2016.

Pada saat ini, kelompok ini beranggotakan hingga 20 orang. Kedua unit kegiatan ini, yakni bank sampah Kasturi dan kelompok wanita tani Lestari diketuai oleh Ibu Sri Asmoroning. Oleh karena, kedua unit kegiatan ini berada di bawah Pembinaan Kesejahteraan Keluarga (PKK) RT 05 RW 12 Karangasem, Desa Condongcatur Kabupaten Sleman. Meskipun demikian, sekilas dalam beberapa pra-survey kami dengan Ibu Sri Asmoroning, untuk kelompok Bank Sampah 
"Kasturi" sudah berdiri sejak lama sehingga organisasi sudah cukup matang dalam pengelolaannya. Sedangkan untuk kelompok wanita tani Lestari, belum terdapatnya sistem pembagian kerja yang efektif dalam kelompok.Hal ini dikarenakan para ibu rumah tangga hanya menganggap sebagai kegiatan sambilan saja.Dalam prasurvey kami dengan Ibu Sri Asmoroning, kami diharapkan untuk membantu kelompok KWT yang baru berdiri satu tahun tersebut.

Permasalahan yang muncul dalam kelompok wanita tani Lestari kemudian dirasakan kami penting untuk dibantu melalui tugas pengabdian masyarakat, karena kami sebagai dosen program studi ilmu pemerintahan Universitas AMIKOM
Yogyakarta. Beberapa permasalahan yang muncul erat-kaitannya dengan kemampuan ilmu pengetahuan berupa ilmu pemerintahan dan skill individu yang dimiliki oleh kami. Selain itu, lokasi yang dekat dengan Universitas AMIKOM Yogyakarta dirasakan juga sangat penting untuk dijadikan dasar pertimbangan utama pengabdian masyarakat yang akan kami lakukan. Oleh karena, pengabdian masyarakat lebih utama apabila bisa bermanfaat bagi masyarakat sekitar Universitas AMIKOM Yogyakarta.

\section{Permasalahan Mitra}

Permasalahan mitra yang terdapat pada pengabdian ini dapat dilihat pada Tabel 1 .

Tabel 1 Permasalahan mitra

\begin{tabular}{cll}
\hline No. & \multicolumn{1}{c}{ Masalah } & Prioritas \\
\hline 1 & Minimnya pengetahuan dan skill dalam pengelolaan administrasi dan & Prioritas \\
& kesekretariatan dalam sebuah organisasi kelompok. & Pertama \\
2 & $\begin{array}{l}\text { Belum adanya sistem pembagian kerja yang efektif dalam kelompok } \\
\text { karena ibu-ibu rumah tangga hanya menganggap sebagai kegiatan }\end{array}$ & Kedua \\
& $\begin{array}{ll}\text { sambilan saja. } \\
\text { Banyaknya produk-produk hasil sampah recycle yang dihasilkan, namun }\end{array}$ & Prioritas \\
& $\begin{array}{l}\text { pemasarannya masih kurang optimal, sehingga banyak produk yang } \\
\text { tidak laku terjual. }\end{array}$ & Ketiga \\
\hline
\end{tabular}

\section{Solusi yang Ditawarkan}

Solusi yang ditawarkan untuk mengatasi permasalahan-permasalahan yang disebutkan sebelumnya diuraikan pada Tabel 2 berdasarkan masing-masing permasalahan yang ditemukan.

Tabel 2 Solusi yang ditawarkan

\begin{tabular}{|c|c|c|}
\hline No. & Masalah & Solusi yang ditawarkan \\
\hline 1 & $\begin{array}{l}\text { Minimnya pengetahuan dan skill } \\
\text { dalam pengelolaan administrasi dan } \\
\text { kesekretariatan dalam sebuah } \\
\text { organisasi kelompok. }\end{array}$ & $\begin{array}{l}\text { 1. Melakukan sosialisasi terkait dengan } \\
\text { pentingnya dan } \\
\text { kesekretariatan bagi organisasi. } \\
\text { 2. Melakukan transfer knowledge terkait alur } \\
\text { prosedur surat masuk dan keluar. } \\
\text { 3. Melakukan pendampingan tata cara teknis } \\
\text { penyusunan surat masuk dan keluar } \\
\text { 4. Melakukan pendampingan dalam filing } \\
\text { document surat baik secara manual maupun } \\
\text { komputer. }\end{array}$ \\
\hline 2 & $\begin{array}{l}\text { Belum adanya sistem pembagian } \\
\text { kerja yang efektif dalam kelompok } \\
\text { karena ibu-ibu rumah tangga hanya }\end{array}$ & $\begin{array}{l}\text { Memberikan pendampingan Capacity } \\
\text { Building khususnya dalam penyusunan } \\
\text { pembagian kerja dalam struktur organisasi }\end{array}$ \\
\hline
\end{tabular}


menganggap sebagai kegiatan sambilan saja.

3 Banyaknya produk-produk hasil sampah recycle yang dihasilkan, namun pemasarannya masih kurang optimal, sehingga banyak produk yang belum laku terjual.

\section{MATERI DAN METODE}

Metode pelaksanaan pengabdian dilakukan dengan metode ceramah melalui pemaparan materi dan tutorial.Pelaksanaan kegiatan pengabdian masyarakat ini dilaksanakan pada 23-26 Februari 2018 di desa Karangasem, Condong Catur, Kabupaten Sleman.

\section{HASIL DAN PEMBAHASAN}

\section{Hasil Pengabdian Masyarakat Unit PKK RT 04 RW 12 Desa Karangasem}

Pengabdian masyarakat yang dilakukan pada Kelompok Wanita Tani (KWT) Desa Karangasem RT 04 RW 12 meliputi berbagai kegiatan, yakni sebagai berikut.

\section{Pelatihan Penguatan Kelembagaan Organisasi melalui penyampaian Materi tentang Pentingnya Struktur Organisasi.}

Aspek utama proses penyusunan sebuah struktur organisasi yaitu departementalisasi dan pembagian kerja (job description). Departementalisasi berarti pengelompokan kegiatan kerja, agar kegiatan-kegiatan yang sejenis dan saling berhubungan dapat dikerjakan bersama.Sedangkan job description merupakan pemerincian tugas pekerjaan, agar setiap individu dalam organisasi bertanggung jawab untuk melaksanakan kegiatan yang terbatas.Di dalam organisasi KWT telah memiliki struktur organisasi, namun belum sepenuhnya dapat dikatakan berjalan dengan baik sebab masing-masing jabatan belum memliki pembagian tugas yang jelas.
Padahal kedua aspek tersebut merupakan dasar proses pengorganisasian untuk mencapai tujuan yang telahditetapkan secara efektif efisien.

\section{Pelatihan Dasar Kesekretariatan dalam organisasi}

Kesekretariatan dalamorganisasi sangat penting terlebih ketika dalam berinteraksi antara lembaga satu dengan lainnya secara formal biasanya melalui media surat. Selama organisasi KWT berdiri sejak 2016, surat-surat dari lembaga/instansi lain hanya disimpan oleh pengurus Kelompok Wanita Tani PKK Desa Karangasem RT 04 RW 12. Sebab mereka belum mengerti mekanisme pengurusan surat masuk dari instansi lain maupun ketika akan membuat surat keluar yang ditujukan kepada instansi lain. Para pengurus KWT khususnya yang menjabat sebagai Sekretaris pun juga belum memiliki pengetahuan dan skill untuk filing document. Dalam pelaksanaan sosialialisasi mengenai materi pengurusan surat masuk dan surat keluar, para pengurus pun sangat antusias menyimak dan mendengarkan. Selain itu, kami dari tim juga melakukan pendampingan dengan Sekretaris. Sekretaris kami tuntun untuk mempraktekkan pencatatan dan pendistribusian surat masuk dan surat keluar, cara penyusunan dan pengisian form disposisi, maupun pengarahan surat. Prosedur surat masuk yang telah kami susun untuk organisasi Kelompok Wanita Tani (KWT) terdapat pada Gambar 1.

Adapun surat keluar yang dibuat untuk ditujukan kepada organisasi ataupun instansi lain harus melalui prosedur seperti pada Gambar 2. 
BAGAN PROSEDURE SURAT MASUK

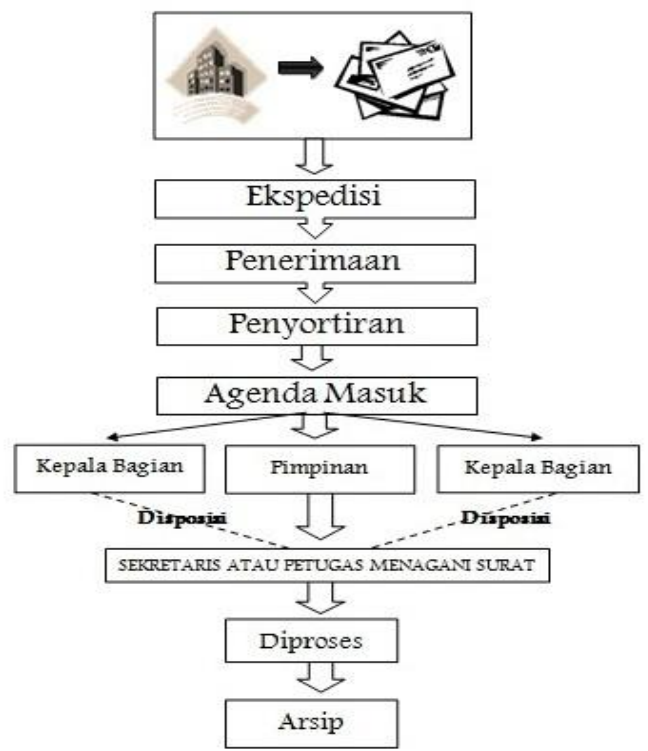

Gambar 1 Prosedur surat masuk

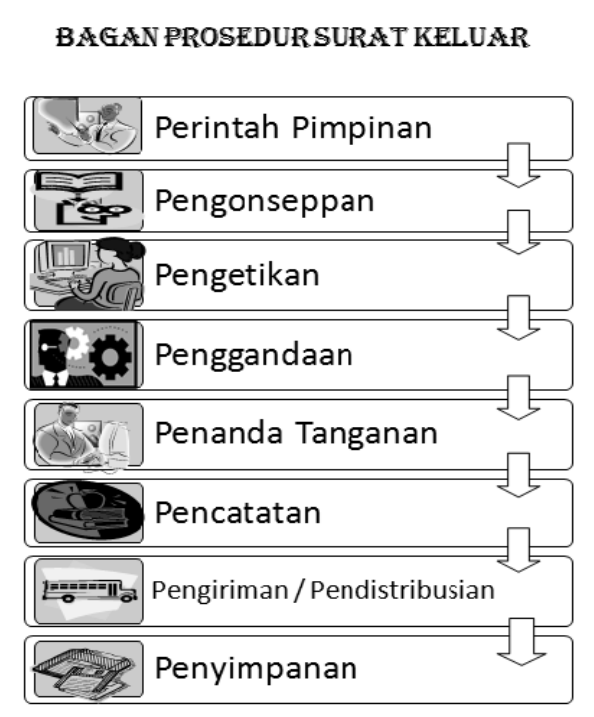

Gambar 2 Prosedur surat keluar

Dari hasil diskusi dengan pengurus PKK Karangasem RT 04 RW 12 muncul beberapa pertanyaan, seperti yang dikemukakan oleh Ibu Kusminiyati mengenai cara penulisan kode surat masuk dan surat keluar dari organisasi. Ibu-ibu sangat antusias dalam mendengarkan materi ini. Terlebih materi ini memang belum pernah didapatkan sebelumnya.

\section{Pelaksanaan pengabdian masyarakat di PKK Desa Karangasem}

Dalam pelaksanaan pengabdian kepada masyarakat dengan tema Capacity Building pada Unit Program PKKDesa Karangasem dapat menghasilkan peningkatan kemampuan dan ketrampilan masyarakat terkait administrasi dan kesekretariatan organisasi serta kelembagaan organisasi khususnya draft pembagian kerja sesuai struktur organisasi yang telah ada. Draft pembagian kerja (Job description) yang telah kami dampingi dalam penyusunannya dapat digunakan oleh Unit Program PKK Desa Karangasem dalam mengoperasionalkan tugas dan wewenang masing-masing jabatan pengurus sehingga tidak terjadi tumpang tindih pekerjaan dalam organisasi.

Dalam program pengabdian masyarakat terkait dengan Capacity Building pada Unit Program PKK Desa Karangasem, terdapat hasil sebagai berikut.

1. Tahap pertama dalam kegiatan ini adalah pengenalan dan penyampaian maksud maupun tujuan dari program pengabdian masyarakat yang dilakukan.Dalam pengenalan tersebut, tujuan yang kami capai adalah bagaimana membangun kepercayaan pemateri dihadapan anggota Kelompok Wanita Tani (KWT) "Lestari" PKK Desa Karangasem.Penyampaian dari maksud dan tujuan program pengabdian masyarakat, bertujuan agar para anggota kelompok KWT "Lestari" PKK Desa Karangasem memahami luaran dari kegiatan pengabdian masyarakat yang kami laksanakan. Para anggota KWT "Lestari" PKK Desa Karangasem diharapkan dapat proaktif dalam kegiatan pelatihan. Adapun para anggota PKK Desa Karangasem diberikan kesempatan untuk melakukan tanya jawab interaktif terkait hal-hal yang dirasa sulit dan menjadi kendala dalam kegiatan rutin yang dilakukan kelompok.

2. Tahap kedua pelaksanaan pelatihan kelembagaan organisasi melalui penyusunan pembagian kerja sesuai 
struktur organisasi yang telah ada.Pada tahap ini menggunakan metode ceramah dan diskusi tanya jawab. Kelompok KWT "Lestari" telah memiliki struktur organisasi yang sudah dilegitimasi oleh Pemerintah Kabupaten Sleman. Meskipun struktur organisasi telah dilegalkan, pengurus KWT "Lestari" belum menyusun pembagian kerja dari masing-masing jabatan. Oleh karena itu, kami membantu memberikan pendampingan dalam penyusunan pembagian kerja tersebut.. Kami menjelaskan urgensitas job description bagi organisasi KWT "Lestari" yang baru berdiri November 2016 lalu. Penyusunan job description ini diharapkan mampu menunjang aktivitas pengurus KWT "Lestari" agar melaksanakan tugas sesuai fungsi, wewenang, dan tanggungjawab pekerjaan. Sehingga kegiatan rutin organisasi mampu berjalan secara efektif dan efisien.

3. Tahap ketiga adalah presentasi terkait dengan pentingnya administrasi dan kesekretariatan dalam organisasi KWT "Lestari".Topik kajiannya tentang pengenalan berbagai macam kegiatan administrasi dan kesekretarian yang dapat menunjang kelancaran organisasi.Tahap ini menggunakan metode ceramah dan tutorial.Para ibuibu pengurus dan anggota KWT diberikan pengetahuan dan ketrampilan dalam pengurusan surat menyurat, baik dari surat masuk maupun surat keluar. Selain itu, dilakukan juga tutorial tata cara penulisan kode dan penomoran yang dicantumkan dalam surat masuk ke dalam organisasi maupun surat keluar untuk instansi eksternal organisasi. Lebih lanjut, tahapan ini para anggota ditekankan agar dapat memahami dan mempraktekkan dengan benar, sehingga mampu mandiri melakukan kegiatan administratif dan kesekretariatan rutin secara profesional. Selain itu, dalam penyampaiannya kelompok KWT "Lestari" mengharapkan agar kegiatan serupa dengan topik lain bisa ditularkan kembali kepada kelompok tersebut.

4. Tahap keempat, kegiatan pengabdian masyarakat ini lebih kepada evaluasi hasil luaran yang didapatkan para ibuibu KWT "Lestari" pasca kegiatan pelatihan dan pendampingan. Kegiatan ini dimaksudkan agar kami sebagai fasilitator mampu mengakomodir saran dan kritik dari masyarakat terhadap kegiatan pelatihan dan pendampingan yang telah kami laksanakan. Mereka menghendaki agar dilakukan program pengabdian berkelanjutan dari kami sebab selama ini memang undangan pelatihan ataupun workshop dari luar untuk organisasi KWT "Lestari" masih sangat minim. Padahal organisasi tersebut masih sangat perlu dibina agar mampu berkembang dan profesional seperti organisasi lain yang telah lama berdiri. Mereka menyadari adanya keterbatasan akses kelompok terhadap informasi dan wawasan sebagai organisasi sosial. Namun, semangat dan motivasi yang tinggi mereka untuk belajar mampu mendorong organisasi KWT "Lestari" menjadi lebih potensial dan produktif menghasilkan karya yang bermanfaat untuk masyarakat.

\section{KESIMPULAN DAN IMPLIKASI}

Pentingnya pelatihan Capacity Building pada Unit Program PKK RT 04 RW 12 Desa Karangasem, Kecamatan Condong Catur demi perbaikan kualitas sumber daya manusia (pengurus dan anggota), upaya untuk mendorong organisasi agar dapat berjalan sesuai denganfungsinya, serta upaya untuk menciptakan kondisi lingkungan yang dibutuhkan oleh organisasi agar dapat berfungsi dengan baik. Penyusunan pembagian tugas yang jelas, akan memberikan tanggung jawab pada setiap anggota organisasi serta dalam melaksanakan tugas akan terjalin kerjasama.Terlebih organisasi tersebut tergolong masih baru. Adapun pelatihan Administrasi dan Kesekretariatan mampu 
menjadi modal pengurus dalam melakukan penataan terhadap pekerjaan organisasi dan tugas-tugas bantuan lainnya. Melalui rangkaian kegiatan pengabdian yang telah kami laksanakan ini diharapkan dapat menunjang kelancaran pencapaian tujuan organisasi dan dapat digunakan untuk mengembangkan organisasi kearah yang lebih baik di masa yang akan datang.

Perlu adanya keberlanjutan program pengabdian masyarakat pada Unit Program PKK RT 04 RW 12 dengan tema yang berbeda untuk menunjang peningkatan kemampuan dan skill para pengurus dan anggota.

\section{DAFTAR PUSTAKA}

Saladin, Djaslim, 2006, Manajemen Pemasaran, Edisi Keempat, Bandung : Linda Karya.

Sukoco,BadriMunir.2007.Manajemen Administrasi Perkantoran Modern. Jakarta:Erlangga.

Suparjati, Dra., 2000. Surat Menyurat Dalam Perkantoran. Kanisius: Yogyakarta.

http://prestasipustakaraya.com/manajeme n-kesekretariatan.html/, diakses pada tanggal 10 Agustus 2017. 